Article

\title{
Effect of Sulfur Content on the Composition of Inclusions and MnS Precipitation Behavior in Bearing Steel
}

\author{
Hongliang Zhang *, Guanghong Feng, Xin Liu, Baoshan Wang and Xuming Liu
}

Metallurgy Department, Central Iron \& Steel Research Institute, Beijing 100081, China; fgh@vip.sina.com (G.F.); ysulx@sina.com (X.L.); 17888843510@163.com (B.W.); 15832555952@163.com (X.L.)

* Correspondence: 154307@163.com; Tel.: +86-010-6218-7215

Received: 30 March 2020; Accepted: 25 April 2020; Published: 27 April 2020

check for updates

\begin{abstract}
MnS inclusions in bearing steel have long been considered to significantly affect the fatigue life of bearing steel. In this paper, the sizes of inclusions in bearing steel with different sulfur contents were analyzed and the precipitation behavior of $\mathrm{MnS}$ was calculated using thermodynamics. Furthermore, the positive role of MnS in bearing steel was discussed. Results showed that when the size of inclusions in bearing steel was increased, the proportion of MnS components in composite inclusions gradually decreased. When the sulfur content was increased, the shape of inclusions changed from a particle shape to a strip shape. With increasing $\mathrm{MnS}$ content, the inclusion ratio of $\mathrm{Al}_{2} \mathrm{O}_{3}$ was significantly reduced in the $\mathrm{Al}_{2} \mathrm{O}_{3}-\mathrm{CaO}-\mathrm{MgO}-\mathrm{MnS}$ quaternary inclusion system, particularly for $\mathrm{MnS}$ proportions greater than $20 \%$. The content of sulfur in bearing steel significantly affects the precipitation temperature of MnS. When sulfur content increases from $0.001 \%$ to $0.007 \%$, the precipitation temperature of MnS increases from $1493 \mathrm{~K}$ to $1633 \mathrm{~K}$ as the precipitation of MnS moves from the austenite solid phase to the liquid and solid phases, and the precipitation size of MnS inclusions significantly increases. The size of oxide inclusions should be controlled to improve MnS wrap oxide inclusions in steel. Based on these results, a composition control with high sulfur levels and low oxygen levels should be adopted to improve the fatigue performance of steel.
\end{abstract}

Keywords: bearing steel; MnS; composite inclusion; thermodynamics; fatigue property

\section{Introduction}

Sulfur is generally considered to be one of the most harmful elements remaining in steel, easily causing the hot embrittlement of steel and reducing its mechanical properties. A common solution to this problem is to increase $w(M n) / w(S)$ to improve the high-temperature ductility of steel, where sulfur can be used in MnS to improve steel and reduce the formation of low melting compounds such as FeS in the austenite grain boundary [1,2].

MnS causes problems in various types of steel. With an increase in sulfur content, the transverse elongation of the carbon steel plate was significantly reduced [3]. During heat treatment at $1523 \mathrm{~K}$, MnS hindered the grain growth of the recrystallization annealing, leading to the deterioration of core loss [4]. The resistance to hydrogen-induced cracking (HIC) of pipeline steel in a wet $\mathrm{H}_{2} \mathrm{~S}$ environment is related to the shape and the distribution of MnS. When the amount of MnS in steel exceeded a certain quantity, the resistance to HIC was significantly reduced [5]. MnS also was a preferential corrosion phase in the structure of weathering steel. Adding sulfides formed by rare earth elements could significantly improve resistance to industrial atmospheric corrosion [6]. Besides these issues, it may also have a beneficial effect on the properties of steel. In free cutting steel, a uniform and fine MnS content could improve cutting performance [7]. Sulfur acts as a highly surface-active element 
that reduces surface tension and the viscosity of steel melts. Sulfides are beneficial in the laser cutting of steel [8].

The most important aspect of bearing steel is its fatigue resistance, and its inclusion size and composition are the most important factors that affect this [9]. The reactions between the oxide inclusions in bearing steel during smelting $[10,11]$, the influence of the inclusion sizes on bearing steel fatigue and other properties [12-14] as well as the use of rare earth elements in bearing steel to modify inclusions $[15,16]$ have all been widely studied. Research on MnS in bearing steel has primarily centered on oxide-sulfide complex inclusions formation mechanism [17-19] and the interaction between MnS and oxides [20].

At present, there are few reports on the positive role of MnS in bearing steel. Drar [21] studied an alloy steel and found that MnS did not contribute to fatigue crack initiation or the crack propagation mechanism. Scurria [22] found that the ratio of the length and thickness of MnS to a certain value significantly affected the fatigue performance of bearing steel.

This paper analyzes the inclusions in bearing steels with different sulfur contents and calculates the precipitation of $\mathrm{MnS}$ in bearing steel by using thermodynamic methods. It discusses the positive role of MnS in bearing steel, which improves its resistance fatigue performance.

\section{Materials and Methods}

Two high-carbon bearing steels produced by an enterprise, grades SUJ2 and GCr15, were selected for testing. Their chemical compositions are shown in Table 1 . The process route of the bearing steel was as follows: a $100 \mathrm{t}$ ultra-high power arc furnace was used for the molten steel smelting, and the steel was produced using an eccentric bottom method. High alkalinity refining treatment and aluminum deoxidation were used in the $100 \mathrm{t}$ refining furnace and vacuum degassing for no less than $20 \mathrm{~min}$ was performed in the $100 \mathrm{t}$ vacuum degassing furnace. A five-machine five-stream continuous casting machine was used for the casting billet production, and a 17-bar continuous rolling mill was used for the hot rolling production.

Table 1. Chemical composition of bearing steel samples.

\begin{tabular}{ccccccccccc}
\hline Elements & C & Si & Mn & P & S & Cr & Mo & Ti & Al & O \\
\hline $1 \#$ & 0.99 & 0.25 & 0.41 & 0.01 & 0.007 & 1.35 & 0.019 & 0.001 & 0.015 & 0.0002 \\
$2 \#$ & 0.96 & 0.27 & 0.39 & 0.009 & 0.001 & 1.57 & 0.01 & 0.002 & 0.014 & 0.0006 \\
\hline
\end{tabular}

Samples of $10 \mathrm{~mm} \times 10 \mathrm{~mm} \times 10 \mathrm{~mm}$ in size were cut from the bearing steel rolled products. After rough grinding, fine grinding and polishing, they were made into metallographic samples. The samples were cut along the rolling direction of the bearing bar and the sampling position of the cross section was at a 1/2 radius. Then, the number, size and composition of the inclusions in the different bearing steel samples were analyzed using an ASPEX SSX-550 automatic scanning electron microscope (ASPEX Inc., Pittsburgh, PA, USA).

The solidification process of $\mathrm{Al}_{2} \mathrm{O}_{3}-\mathrm{CaO}-\mathrm{MgO}-\mathrm{MnS}$ inclusions with different $\mathrm{MnS}$ contents was calculated by using Factsage 7.3 thermodynamics software (Thermfact/CRCT, Montreal, QC, Canada and GTT-Technologies, Ahern, Germany), which was authorized by the Central Iron and Steel Research Institute. The calculation process mainly involved two databases, FToxid and FSstel. The precipitation behavior of MnS in the bearing steel was analyzed using the metallurgical thermodynamic method.

A three-point contact fatigue test was performed suing a ball-rod contact fatigue test machine (Nantong University, Jiangsu, China), which used 20 pieces of two bearing steel products with a diameter of $10 \mathrm{~mm}$. The loading times to the contact of the steel bar of the test machine were $2.49 \times 10^{5}$ per hour, at a loading strength of $3900 \mathrm{~N}$ and a speed of $1800 \mathrm{r} / \mathrm{min}$. The fatigue test results determined the fatigue life performance of the two bearing steels.

The examination of the inclusion in bearing steel was conducted using ASPEX automatic scanning electron microscopes manufactured by the ASPEX company in the United States, which perform the 
basic function of conventional scanning electron microscopes as well as the calculation of automatic statistics for the inclusion information from the sample cross-section. The working principle of the ASPEX SEM is shown in Figure 1. The accelerating voltage adjustment range of the equipment was $0.2-25 \mathrm{kV}$ and the amplification was 20-250,000 times. The inclusion size range of the device was $0.07 \mu \mathrm{m}-8 \mathrm{~mm}$. Because of the detection efficiency and critical size of inclusions in bearing steel fatigue failure, the minimum size of the inclusions detected in this experiment was $1 \mu \mathrm{m}$. The equipment accurately determined the maximum diameter, minimum diameter and the surface area of the inclusions suing eight strings passing through the center of the inclusions [23].

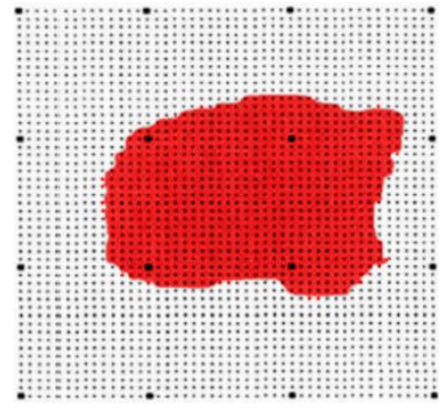

(a)

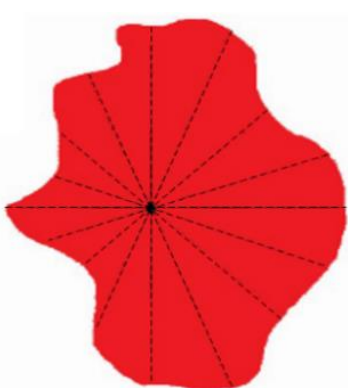

(b)

Figure 1. Working principle of ASPEX: (a) search and measure grid; (b) typical characteristic image.

\section{Results and Discussion}

\subsection{Morphology of Inclusions in Bearing Steel with Different Sulfur Contents}

The morphology and size characteristics of the inclusions in bearing steels 1 and 2 are shown in Figures 2 and 3. In these figures, Dmax indicates the maximum diameter of inclusion ( $\mu \mathrm{m})$, Dmin indicates the minimum diameter of inclusion $(\mu \mathrm{m})$ and area indicates the surface area of inclusion $\left(\mu \mathrm{m}^{2}\right)$. Compared with the traditional inspection method, ASPEX can more directly calculate the area of inclusions and more accurately analyze the size and morphology characteristics of inclusions in the steel. The inclusions in steel 1 are mostly strip-shape, whereas the inclusions in steel 2 are rounder and more elliptical.

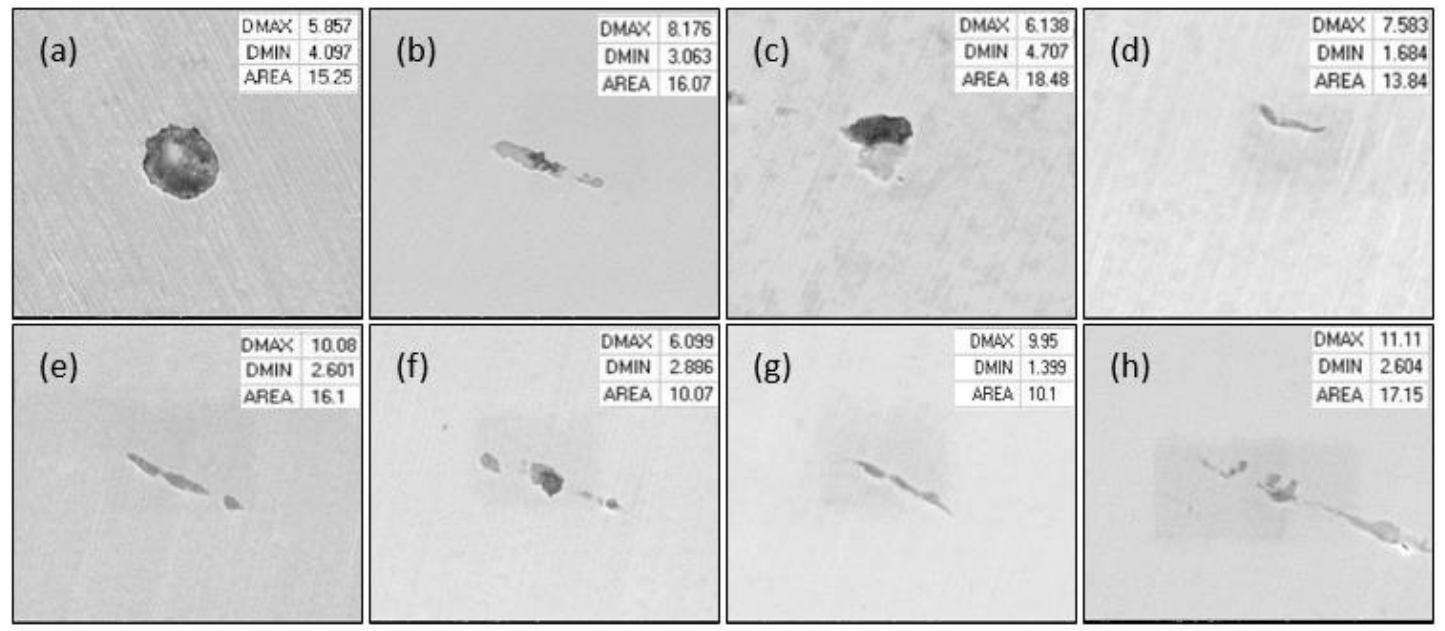

Figure 2. Shape and size of the inclusions in bearing steel 1: (a) round; (b) strip and round; (c) polygonal; (d) Strip; (e) strip; (f) strip and round; (g) strip; (h) strip. 


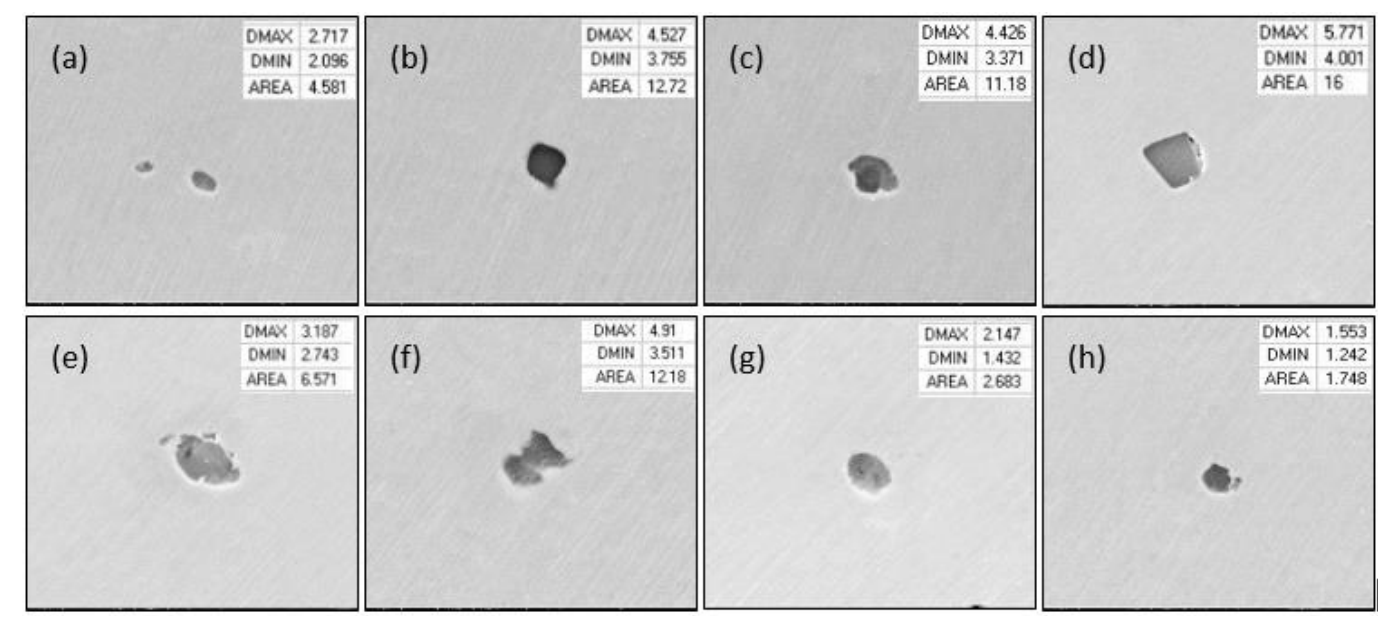

Figure 3. Shape and size of the inclusions in bearing steel 2: (a) round; (b) round; (c) round and ellipse; (d) rhombic; (e) ellipse; (f) polygonal; (g) round; (h) round.

The energy spectrum inspections of the typical inclusions in bearing steels 1 and 2 are shown in Figures 4 and 5. The steel 1 sample was mainly composed of $\mathrm{MnS}$ and $\mathrm{Al}_{2} \mathrm{O}_{3}$ composite inclusions, with a small amount of $\mathrm{MgO}, \mathrm{CaO}$ and $\mathrm{MnO}$. The composition of the inclusions in the steel 2 sample mainly included composite inclusions of granular calcium aluminate and $\mathrm{MnS}$, with the composition being largely $\mathrm{Al}_{2} \mathrm{O}_{3}, \mathrm{MgO}, \mathrm{CaO}$ and $\mathrm{MnS}$.
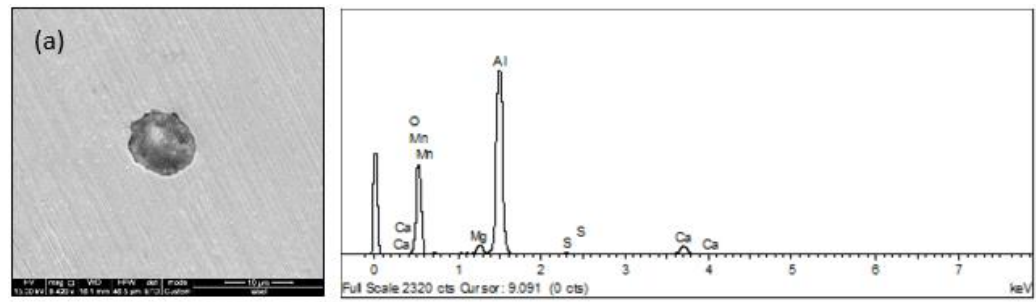

(b)
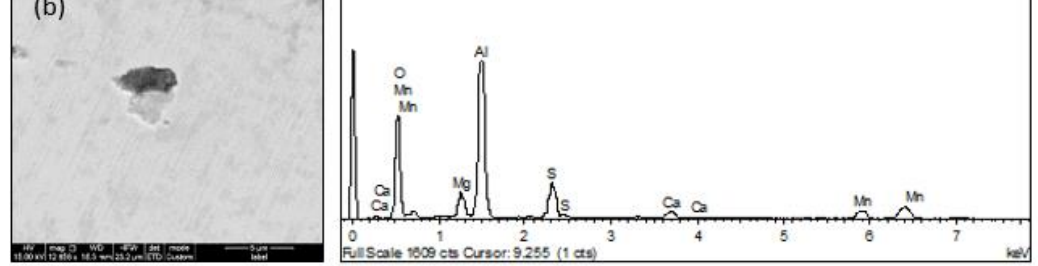

(c)

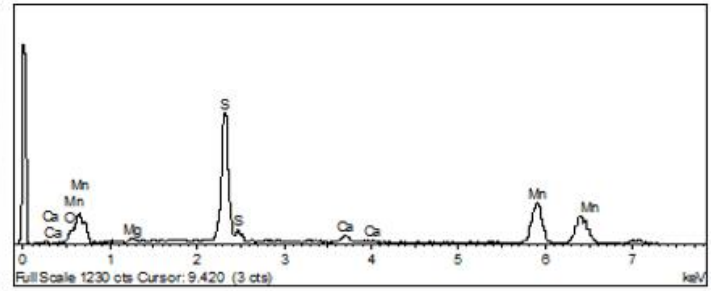

(d)

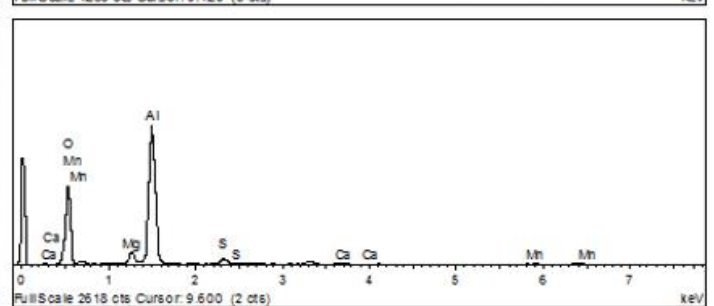

Figure 4. EDS analysis of bearing steel 1: (a) $\mathrm{Al}_{2} \mathrm{O}_{3}-\mathrm{MgO}-\mathrm{CaO}$; (b) $\mathrm{Al}_{2} \mathrm{O}_{3}-\mathrm{MgO}-\mathrm{CaO}-\mathrm{MnS}$; (c) $\mathrm{MnS}$; (d) $\mathrm{Al}_{2} \mathrm{O}_{3}-\mathrm{MgO}$. 

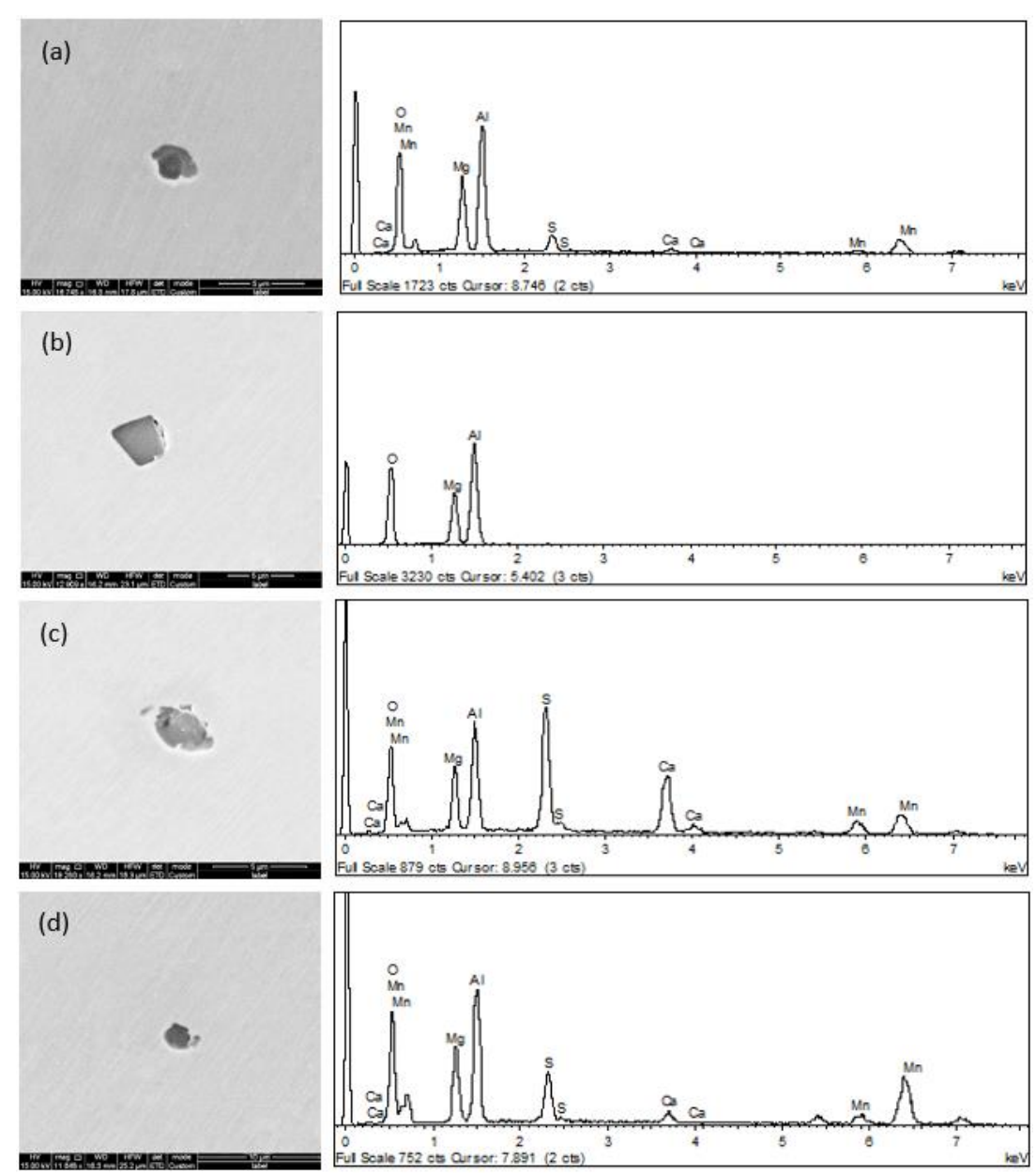

Figure 5. EDS analysis of bearing steel 2: (a) $\mathrm{Al}_{2} \mathrm{O}_{3}-\mathrm{MgO}-\mathrm{MnS}$; (b) $\mathrm{Al}_{2} \mathrm{O}_{3}-\mathrm{MgO}$; (c) $\mathrm{Al}_{2} \mathrm{O}_{3}-\mathrm{MgO}-\mathrm{CaO}-$ $\mathrm{MnS}(\mathrm{CaS}) ;(\mathbf{d}) \mathrm{Al}_{2} \mathrm{O}_{3}-\mathrm{MgO}-\mathrm{CaO}-\mathrm{MnS}$.

Using ASPEX to scan the $10 \mathrm{~mm} \times 10 \mathrm{~mm}$ areas on the surfaces of each sample line by line, the inclusions in the bearing steel samples was counted and the content of MnS in each inclusion was analyzed suing EDS of ASPEX, as shown in Table 2. To facilitate the calculation of the statistics for $\mathrm{MnS}$ in inclusions, the CaS in inclusions was ignored because of the minuscule content of $\mathrm{Ca}$ in the inclusions of bearing steel.

Thirty inclusions were found on the cross-section of sample 1, of which inclusions containing MnS accounted for $96 \%$ of the total quantity. One hundred twenty-eight inclusions were found on the cross-section of sample 2 and MnS-containing inclusions accounted for $81.3 \%$ of this quantity. It can be seen that $\mathrm{MnS}$ is an important component of the composite inclusions in bearing steel. Figure 6 shows a statistical analysis of the shape of the inclusions from samples 1 and 2 . When the ratio of the maximum diameter to the minimum diameter of the inclusion satisfied Dmax/Dmin $>2$, the composite inclusions were considered to be a long-shaped. When $\operatorname{Dmax} / \operatorname{Dmin}<2$, the composite inclusions were considered to be circular or oval. As can be seen in Figure 6, the proportion of strip-shaped inclusions in sample 1 is $86.7 \%$ and the proportion of strip-shaped inclusions in sample 2 is $7.1 \%$. This shows that the sulfur content of bearing steel significantly affected the shape of the composite inclusions in the steel.

Some literature has shown that the size of endogenous inclusions $(<50 \mu \mathrm{m})$ during the refining and deoxidation of bearing steel decreases significantly as the total oxygen content is reduced [24]. However, the current study found that when the sulfur content in bearing steel was significantly increased, the size of the inclusions in the steel did not decrease. These inclusions mainly consisted of 
MnS composite inclusions. Therefore, it is very important to understand the effect of MnS on bearing steel composite inclusions.

Table 2. Statistics of the inclusions in the different bearing steel samples per square centimeter.

\begin{tabular}{ccccccc}
\hline $\begin{array}{c}\text { Inclusion } \\
\text { Composition }\end{array}$ & TiN & MnS & $\begin{array}{c}\text { Complex } \\
\text { Inclusion } \\
\text { with MnS }\end{array}$ & $\begin{array}{c}\text { No MnS } \\
\text { Complex } \\
\text { Inclusion }\end{array}$ & $\begin{array}{c}\text { Total } \\
\text { Number of } \\
\text { Inclusions }\end{array}$ & $\begin{array}{c}\text { Percentage } \\
\text { of MnS } \\
\text { Inclusions }\end{array}$ \\
\hline $1 \#$ & 0 & 7 & 22 & 1 & 30 & $96.7 \%$ \\
$2 \#$ & 2 & 0 & 104 & 22 & 128 & $81.3 \%$ \\
\hline
\end{tabular}

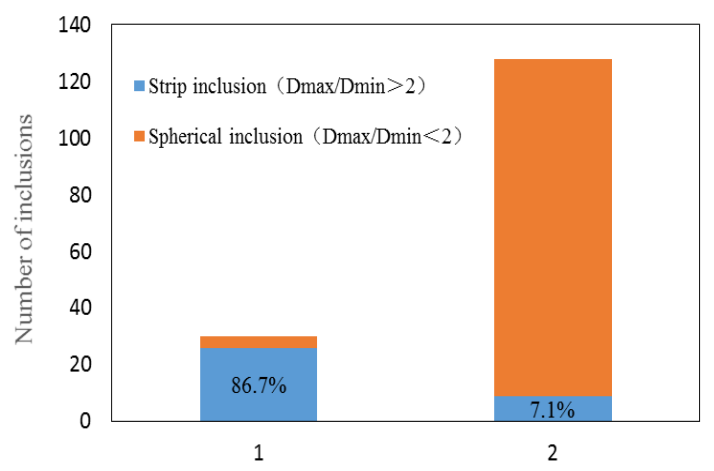

Figure 6. Dmax/Dmin of the inclusions in the bearing steel samples 1 and 2.

\subsection{Relationship between Size and Composition of Inclusions in Bearing Steel}

It can be concluded from the ASPEX inspection that the majority of the inclusions in bearing steel were composite inclusions containing MnS. The size distribution of the composite inclusions in bearing steel and the relationship between the size and ratio of $\mathrm{MnS}$ in the inclusions are shown in Figure 7. The area containing the most inclusions in sample 1 was found at $5-20 \mu \mathrm{m}^{2}$, with the maximum mass fraction of $\mathrm{MnS}$ in the composite inclusions being 37\%. The area with the most inclusions in sample 2 was found at 2-10 $\mu^{2}$, with the maximum mass fraction of $\mathrm{MnS}$ in the composite inclusions at $16 \%$. The proportion of $\mathrm{MnS}$ in the composite inclusions in sample 1 was larger than that in those in sample 2. It can be seen that with an increase in the size of the inclusions in bearing steel, the proportion of $\mathrm{MnS}$ in the impurities gradually decreases. Both bearing steels showed the same regularity. Therefore, MnS has an obvious wrap effect on the inclusion of small-scale oxides in bearing steel.

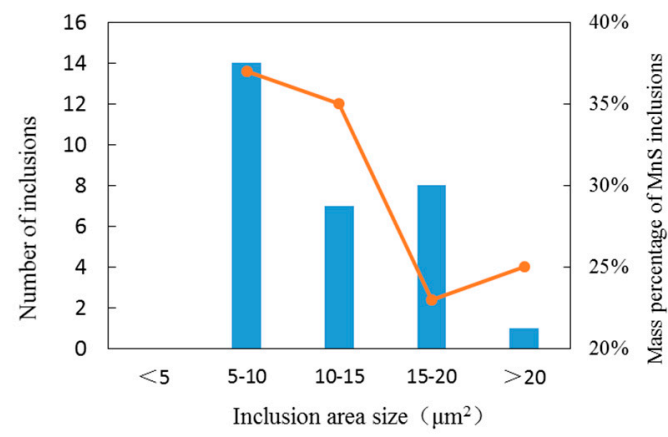

(a)

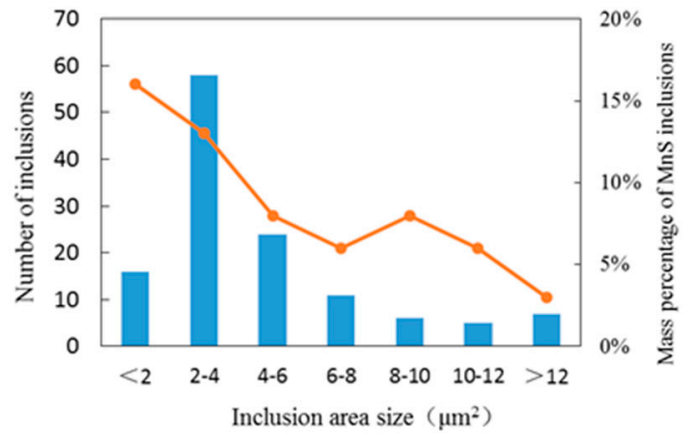

(b)

Figure 7. Size distribution and MnS ratio of composite inclusions in bearing steel: (a) sample 1; (b) sample 2 .

It has been reported [22] that within a certain range of inclusion sizes and Dmax/Dmin ratios of MnS in steel, MnS can wrap oxide inclusions, which could effectively improve the thermoplasticity of 
steel without reducing its fatigue life. In the current study, it was found that the effect of coating oxides with MnS was worse when only the sulfur content was increased, but the total oxygen content in steel was not controlled throughout the production process.

To analyze the relationship between the size of the composite inclusions and the various components in bearing steel, the $\mathrm{Al}_{2} \mathrm{O}_{3}-\mathrm{MgO}-\mathrm{CaO}-\mathrm{MnS}$ quadruple of composite inclusions in bearing steel samples 1 and 2 was analyzed, as shown in Figure 8.

It was found that when the total oxygen content in bearing steel was low, there were fewer $\mathrm{CaO}$ and $\mathrm{MgO}$ inclusions in the bearing steel sample 1 composite inclusions, leaving mainly MnS and $\mathrm{Al}_{2} \mathrm{O}_{3}$ composite inclusions. The composition of the inclusions in sample 2 changed from $\mathrm{Al}_{2} \mathrm{O}_{3}-\mathrm{MgO}-\mathrm{CaO}-\mathrm{MnS}$ to $\mathrm{MgAl} 2 \mathrm{O} 4$ spinel inclusions when size of composite inclusions was increased. The nucleation of $\mathrm{MnS}$ on $\mathrm{MgAl} 2 \mathrm{O} 4$ spinel inclusions was caused by a lattice disorder mechanism, which reflected the heterogeneous nucleation and growth of $\mathrm{MnS}$ on the spinel inclusions [17]. When the sulfur content in bearing steel sample 2 was low, the proportion of MnS in the small inclusions was high, but was low in the large inclusions. Although large-scale oxide inclusions are the main factor in the fatigue failure of bearing steel, MnS has an obvious effect in low sulfur bearing steel on the inclusion of small-scale oxides, which is not conducive to the positive role of sulfur.

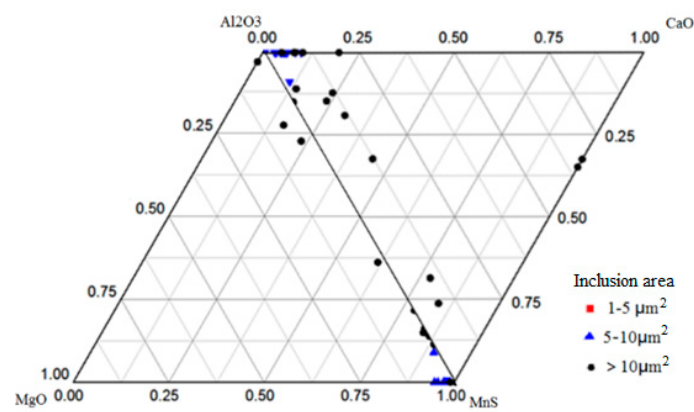

(a)

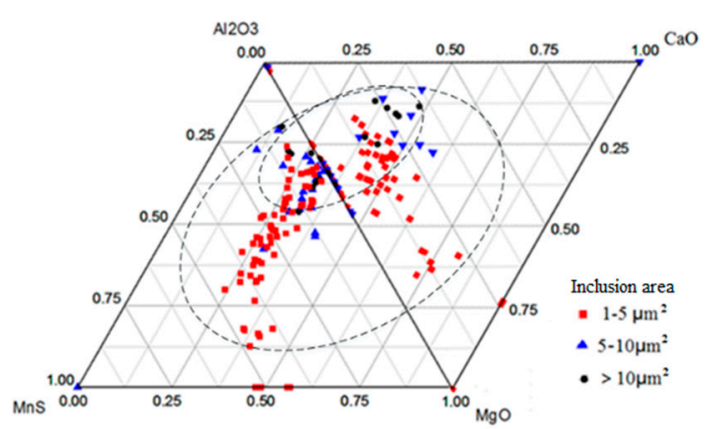

(b)

Figure 8. Ternary phase diagram of the composite inclusion components $\mathrm{Al}_{2} \mathrm{O}_{3}, \mathrm{MgO}, \mathrm{CaO}, \mathrm{MnS}$ in bearing steel: (a) sample 1; (b) sample 2 .

\subsection{Thermodynamic Calculation of $\mathrm{Al}_{2} \mathrm{O}_{3}-\mathrm{CaO}-\mathrm{MgO}-\mathrm{MnS}$ with Different $\mathrm{MnS}$ Contents}

The liquid phase projection diagram of the $\mathrm{Al}_{2} \mathrm{O}_{3}-\mathrm{CaO}-\mathrm{MgO}-\mathrm{MnS}$ system was calculated using the Factsage thermodynamics software (Thermfact/CRCT, Montreal, QC, Canada and GTT-Technologies, Ahern, Germany), and the influence of $5 \%, 10 \%, 20 \%$ and $40 \% \mathrm{MnS}$ contents on the composition of quaternary inclusions were analyzed, as shown in Figure 9. It can be seen that when the MnS content was increased, the low melting point region where the inclusions were expected to be in the liquid phase decreased gradually and moved away from the $\mathrm{Al}_{2} \mathrm{O}_{3}$ composition.

The most critical factors affecting the fatigue life of bearing steel are the hard inclusions with the largest particle sizes such as $\mathrm{Al}_{2} \mathrm{O}_{3}$ and TiN [25]. When the MnS content increases, the proportion of $\mathrm{Al}_{2} \mathrm{O}_{3}$ in $\mathrm{Al}_{2} \mathrm{O}_{3}-\mathrm{CaO}-\mathrm{MgO}$ decreases, and the proportion of $\mathrm{CaO}$ increases. When the $\mathrm{Al}$ content in bearing steel is held constant, increasing the $\mathrm{S}$ content can cause the $\mathrm{Al}_{2} \mathrm{O}_{3}$ in the inclusion to become finer and more dispersed, especially when the MnS proportions reach more than $20 \%$.

The effect of MnS on the composition of the inclusions in steel is mainly achieved by affecting the levels of $\mathrm{Ca}$ and $\mathrm{Mg}$. The order in which the elements in steel combine with $\mathrm{S}$ to form sulfides is $\mathrm{Ca}$, $\mathrm{Mg}$, $\mathrm{Ti}, \mathrm{Mn}$ and then Fe. When the $\mathrm{S}$ content in steel increases, it promotes the formation of $\mathrm{CaS}$ and $\mathrm{MgS}$, which causes the reduction of $\mathrm{CaO}$ and $\mathrm{MgO}$. It had been reported that when the proportion of $\mathrm{CaO}$ decreased, the area of the low-temperature liquid phase region decreased in the quaternary inclusion system of $\mathrm{MnO}-\mathrm{CaO}-\mathrm{SiO}_{2}-\mathrm{Al}_{2} \mathrm{O}_{3}$ [26]. 
Therefore, the proper increase of sulfur content in bearing steel, which increases the proportion of $\mathrm{MnS}$ in inclusions, can reduce the proportion of $\mathrm{Al}_{2} \mathrm{O}_{3}$ in the composite inclusions. This is very beneficial to improve the fatigue strength of bearing steel.

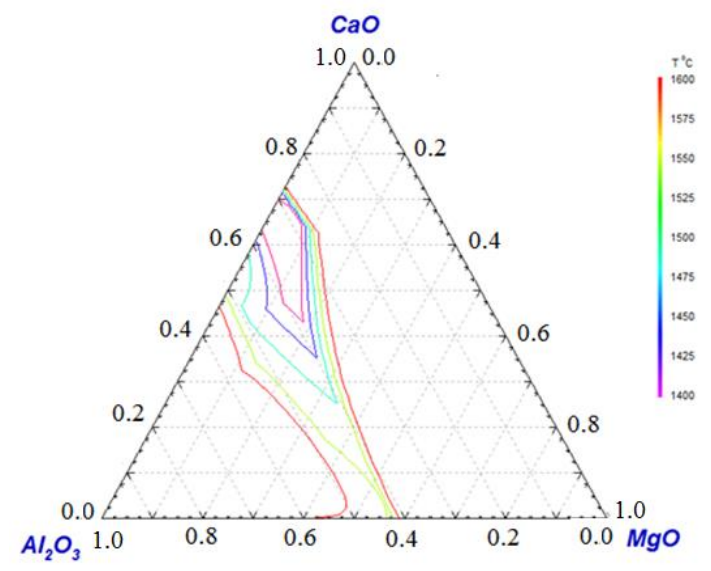

(a)

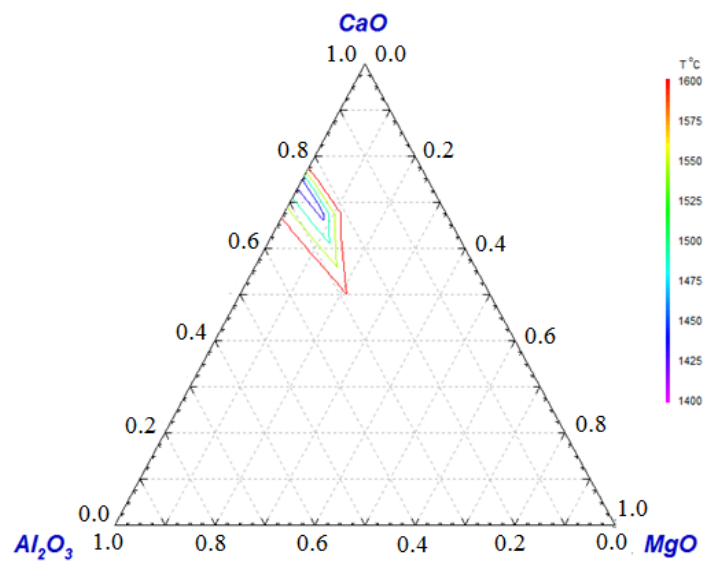

(c)

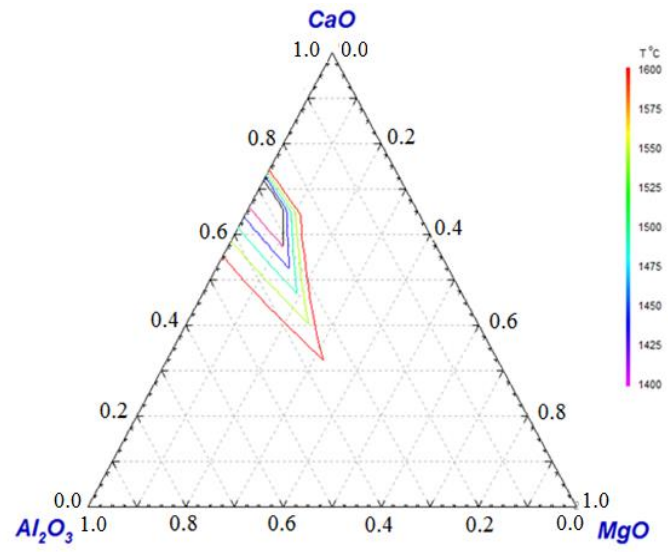

(b)

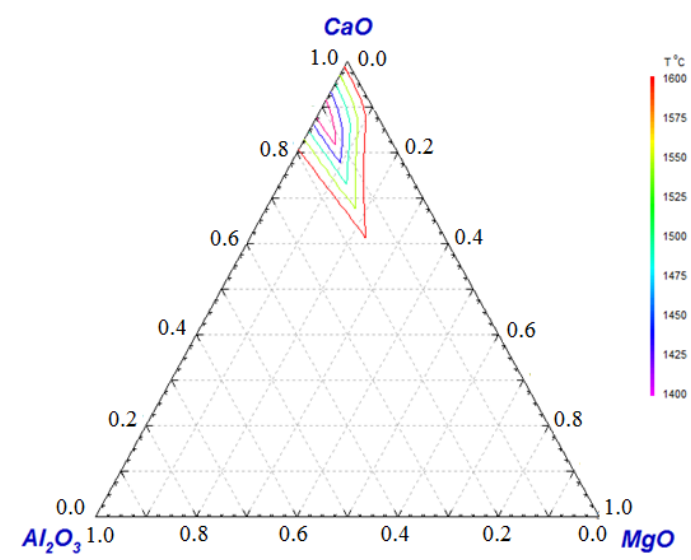

(d)

Figure 9. Liquid phase projection of the $\mathrm{Al}_{2} \mathrm{O}_{3}-\mathrm{CaO}-\mathrm{MgO}-\mathrm{MnS}$ system with different $\mathrm{MnS}$ contents: (a) $5 \% \mathrm{MnS}$; (b) $10 \% \mathrm{MnS}$; (c) 20\% MnS; (d) $40 \% \mathrm{MnS}$.

\subsection{Thermodynamic Analysis of MnS Precipitation Behavior of Bearing Steel}

In this section, the precipitation behavior of MnS and the mass fraction change of MnS precipitation during the solidification of two experimental steels were calculated suing metallurgical thermodynamics. The calculation of the mass fraction of precipitated MnS does not consider any kinetics of the precipitation or the growth rate of MnS inclusions.

The reaction Equations (1) [27] for the formation of MnS in the molten steel and the reaction equilibrium constant (2) for MnS were obtained, and the equilibrium reaction Equation (3) was found to be as follows:

$$
\begin{gathered}
{[\mathrm{S}]+[\mathrm{Mn}]=\operatorname{MnS}(\mathrm{s}), \Delta G \Theta=-168822+98.87 T,(\mathrm{~K})} \\
K_{M n S}=\frac{a_{M n S}}{a_{[M n]} a_{[\mathrm{S}]}}=\frac{1}{f_{M n} w[\mathrm{Mn}] f_{S} w[\mathrm{~S}]} \\
\log K_{M n S}=\frac{-\Delta G^{\Theta}}{2.3 R T}=\frac{8827.9}{T}-5.17
\end{gathered}
$$


where $K_{M n S}$ represents the reaction equilibrium constant of MnS, T represents the reaction temperature $(\mathrm{K})$, R represents the ideal gas constant $8.314 \mathrm{~J} /(\mathrm{mol} \cdot \mathrm{K})$, and $f_{M n S}$ and $f_{S}$ are the activity coefficients of $\mathrm{Mn}$ and $\mathrm{S}$ in molten steel, respectively.

According to Wagner's first-order interaction coefficient, Raoult's law and Henry's Law, the activity coefficient $f_{i}$ of the solidification front is as follows:

$$
\log f_{i(1873 K)}=\sum\left(e_{i(1873 K)}^{j} w[j]\right)
$$

The influence of the different elements in molten steel on the activity coefficients of Mn and S is shown in Table 3.

Table 3. Interaction coefficients of Mn and S in molten steel at $1873 \mathrm{~K}$ [28].

\begin{tabular}{ccccccccccc}
\hline $\boldsymbol{e}_{\boldsymbol{i}}^{j}$ & $\mathbf{C}$ & $\mathbf{S i}$ & $\mathbf{M n}$ & $\mathbf{P}$ & $\mathbf{S}$ & $\mathbf{C r}$ & $\mathbf{M o}$ & $\mathbf{A l}$ & $\mathbf{O}$ & $\mathbf{T i}$ \\
\hline $\mathrm{Mn}$ & -0.07 & 0 & 0 & -0.0035 & -0.048 & 0 & 0 & 0 & -0.083 & 0 \\
$\mathrm{~S}$ & 0.11 & 0.063 & -0.0026 & 0.029 & -0.028 & -0.011 & 0.0027 & 0.035 & -0.27 & -0.072 \\
\hline
\end{tabular}

The solid solubility products of bearing steel sample 1 and 2 in the MnS equilibrium state were calculated to be as follows:

$$
\log (w[S] w[M n])=-\frac{8827.9}{T}+5.13
$$

Moreover, considering the solid-state rate during solidification, temperature changes at the solidification front are as follows:

$$
T=T_{0}-\frac{T_{0}-T_{L}}{1-f_{S 0}\left(T_{L}-T_{S}\right) /\left(T_{0}-T_{S}\right)}
$$

$T_{0}$ represents the melting point of pure iron, whereas $T_{L}$ represents the liquidus temperature of steel, $T_{s}$ represents the solidus temperature of steel, $f_{s 0}$ represents the solid phase ratio and T represents the liquidus zone temperature at the solidification front. $T_{L}$ and $T_{S}$ were calculated suing the Factsage software. The calculated result of $T_{L}$ in sample 1 was approximately $1724 \mathrm{~K}$ and $T_{S}$ was approximately $1610 \mathrm{~K}$. The values of $T_{L}$ and $T_{S}$ in sample 2 were 1727 and $1622 \mathrm{~K}$, respectively. Formulas (5) and (6) can be used to calculate the activity product of $\mathrm{Mn}$ and $\mathrm{S}$ in the equilibrium during the solidification process of molten steel.

Solute segregation should be considered when calculating the actual activity product of Mn and S during solidification. The components after segregation can be solved for using the Scheil equation of solute redistribution as follows:

$$
\begin{gathered}
w[M n]^{\prime}=w[M n] \cdot\left(1-f_{S 0}\right)^{K_{M n}-1} \\
w[S]^{\prime}=w[S] \cdot\left(1-f_{S 0}\right)^{K_{S}-1}
\end{gathered}
$$

where $w[\mathrm{Mn}]$ represents the mass fraction of $\mathrm{Mn} ; w[S]$ represents the mass fraction of $S, f_{s 0}$ presents the solid phase ratio, and $K_{M n}$ and $K_{S}$ are the equilibrium partition coefficients of Mn and $S$ in bearing steel, the values of which are shown in Table 4.

Table 4. Diffusion coefficient and equilibrium partition of Mn and S [29].

\begin{tabular}{ccc}
\hline Element & $\boldsymbol{D}_{\boldsymbol{s}}^{r}\left(\mathrm{~cm}^{2} / \mathbf{s}\right)$ & $\boldsymbol{K}$ \\
\hline $\mathrm{Mn}$ & $0.055 \operatorname{Exp}(-249366 / \mathrm{RT})$ & 0.785 \\
$\mathrm{~S}$ & $2.4 \operatorname{Exp}(-223426 / \mathrm{RT})$ & 0.035 \\
\hline
\end{tabular}

The curve of the MnS solubility product in an equilibrium state and the actual solubility product under the segregation of bearing steel are shown in Figure 10. The curves of the solid phase ratio 
with temperature during the solidification of bearing steel samples 1 and 2 are shown in Figure 11, and the mass fraction of MnS precipitated out during the cooling is shown in Figure 12. During the solidification process of bearing molten steel, the actual solubility product of MnS increased and the equilibrium solubility product decreased. When the actual solubility product of MnS was greater than the solubility product in the equilibrium, MnS could be precipitated from the steel.

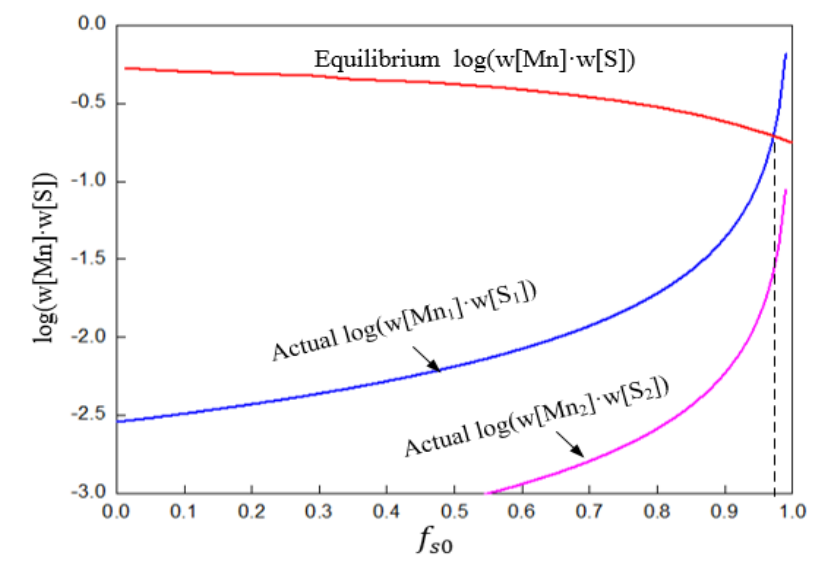

Figure 10. Solubility product of MnS in the equilibrium and the real state with solid fraction.

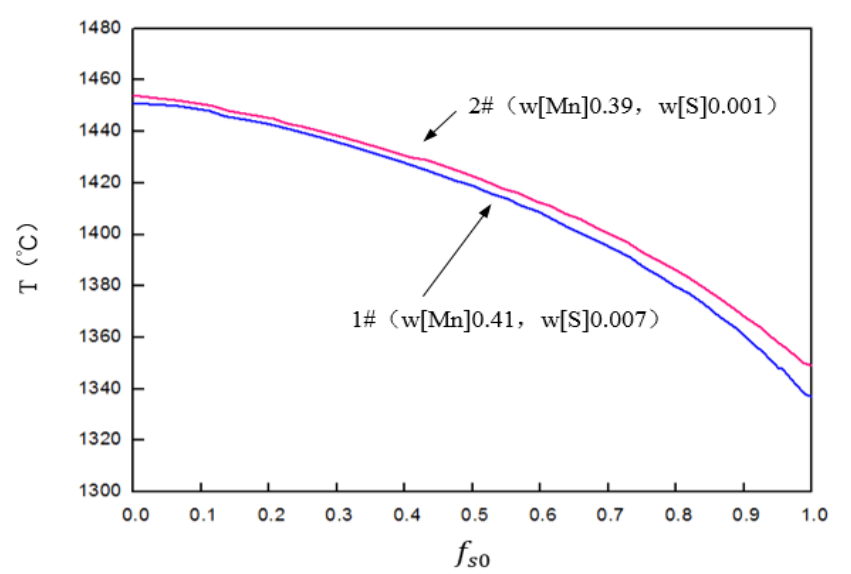

Figure 11. Solid fraction changing with temperature during the solidification.

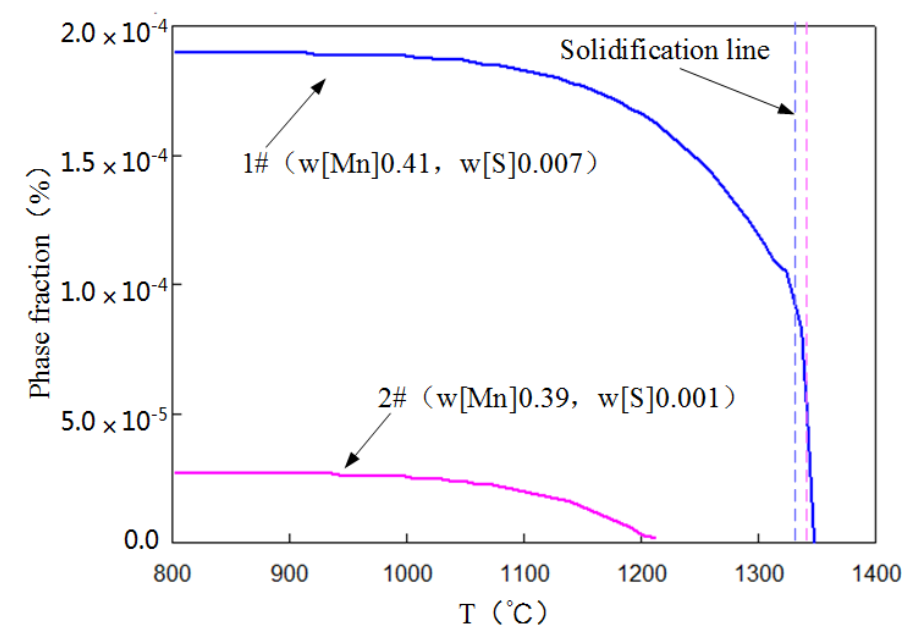

Figure 12. Mass fraction of MnS changing with temperature during the solidification.

The sulfur content in bearing steel significantly affected the precipitation temperature of MnS. The MnS of steel sample 1 began to precipitate at a temperature of $1633 \mathrm{~K}$ when the solid phase ratio of 
molten steel was 0.96. After solidification, the amount of MnS precipitated was close to $50 \%$, with the rest precipitating in the solid phase. During the solidification process of steel sample 2, MnS did not reach the thermodynamic conditions for precipitation. Precipitation did not occur but did begin in the austenite phase at $1493 \mathrm{~K}$. It is for this reason that the amount of MnS in sample 2 was significantly smaller than that of sample 1, which was consistent with the previous results.

\subsection{Fatigue Properties of Bearing Steel with Different Sulfur Contents}

A contact fatigue test was carried using a ball bar tester for the two types of bearing steel with different compositions. The test results are shown in Table 5. The $\mathrm{P}-\mathrm{N}$ curve of the rolling contact fatigue test can be used to judge the fatigue performance of the two types of bearing steels.

Table 5. Contact cycle times of the bearing steel fracture (cycles).

\begin{tabular}{ccccccccccc}
\hline Sample & $\mathbf{1}$ & $\mathbf{2}$ & $\mathbf{3}$ & $\mathbf{4}$ & $\mathbf{5}$ & $\mathbf{6}$ & $\mathbf{7}$ & $\mathbf{8}$ & $\mathbf{9}$ & $\mathbf{1 0}$ \\
\hline $1 \#$ & $3.45 \times 10^{6}$ & $2.94 \times 10^{6}$ & $2.65 \times 10^{6}$ & $2.68 \times 10^{6}$ & $0.83 \times 10^{6}$ & $1.07 \times 10^{6}$ & $1.34 \times 10^{6}$ & $0.57 \times 10^{6}$ & $1.52 \times 10^{6}$ & $0.42 \times 10^{6}$ \\
2\# & $1.63 \times 10^{6}$ & $1.12 \times 10^{6}$ & $0.98 \times 10^{6}$ & $1.24 \times 10^{6}$ & $1.09 \times 10^{6}$ & $1.83 \times 10^{6}$ & $0.69 \times 10^{6}$ & $0.48 \times 10^{6}$ & $0.75 \times 10^{6}$ & $1.29 \times 10^{6}$ \\
\hline
\end{tabular}

The rolling contact fatigue life obeys the two-parameter Weibull function [30], with the following expression:

$$
P(N)_{S}=1-e^{-\left(\frac{N}{V S}\right)^{b}}
$$

where $P(N)_{S}$ is the probability that the sample life is less than $N$ at a certain stress level (\%), $b$ represents the slope of the Weibull distribution, $N$ represents the number of stress cycles (fatigue life), $V s$ is the characteristic life of the Weibull distribution, i.e., the fatigue life when failure probability is $63.2 \%$.

The characteristic value of bearing steel fatigue life and the slope of the Weibull curve are shown in Table 6.

Table 6. Characteristic value of the fatigue life and the Weibull slope of bearing steel by different standards [31].

\begin{tabular}{ccc}
\hline Sample & $\mathbf{L}_{\mathbf{1 0}}$ & $\boldsymbol{k}$ \\
\hline SUJ2 & $0.685 \times 10^{6}$ & 2.214 \\
GCr15 & $0.543 \times 10^{6}$ & 3.269 \\
\hline
\end{tabular}

Finally, the P-N curves of the rolling contact fatigue lives of bearing steel are shown in Figure 13. It can be seen that the rolling contact fatigue life of sample 1 is longer than that of sample 2.

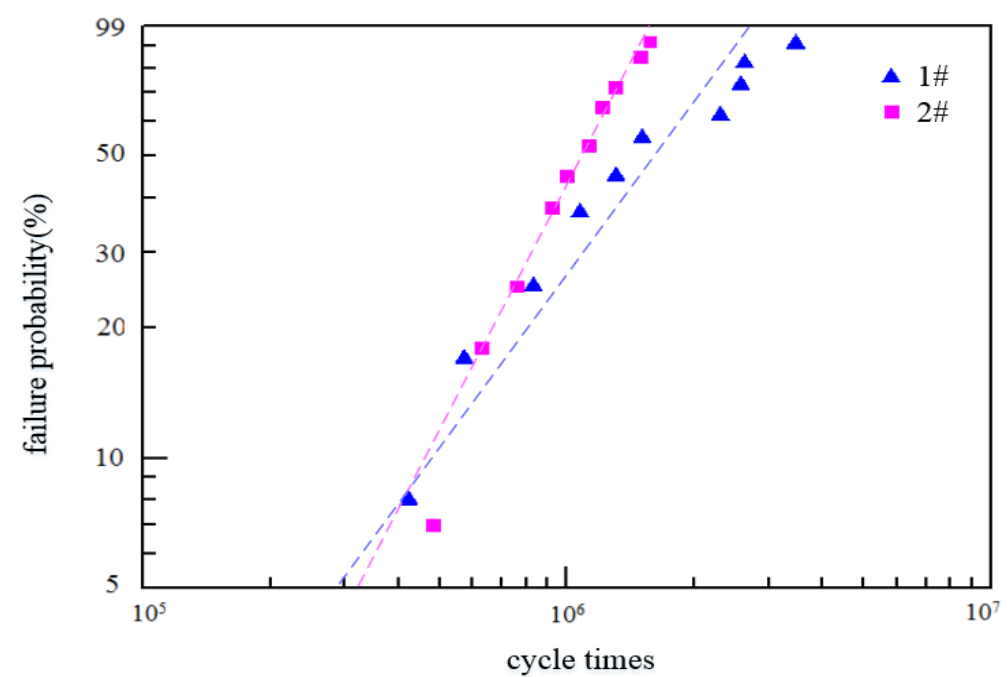

Figure 13. $\mathrm{P}-\mathrm{N}$ curves of the rolling contact fatigue experiments on steel samples 1 and 2. 
Composite inclusions in bearing steel composed of oxide and sulfide control the fatigue performance of high cleanliness bearing steel. The fatigue performance of bearing steel with a low sulfur content $(0.001 \% \mathrm{~S})$ is independent of $\mathrm{MnS}$ inclusions, whereas the fatigue performance of bearing steel with a high sulfur content $(0.006 \% \mathrm{~S})$ will show anisotropy, which leads to transverse fatigue failure in the specimen [32,33]. The fatigue life of bearing steel depends mainly on the chemical composition of oxide in it. After the fatigue test, it was found that there were cavities around $\mathrm{Al}_{2} \mathrm{O}_{3}$ and $\mathrm{Al}_{2} \mathrm{O}_{3} \cdot \mathrm{CaO}$ inclusions, but no cavities were near $\mathrm{MnS}$ inclusions and various composite inclusions [9].

Therefore, it is reasonable to assume that a composition of high sulfur and low oxygen can improve the fatigue property of bearing steel. In this study, it was found that the proportion of MnS in inclusions in bearing steel decreased when inclusion size increased, and that MnS had an obvious wrap effect on small-scale oxide inclusions. When considering an increase in sulfur content in steel to improve the fatigue property, the total oxygen content in the steel must be controlled in a lower range. Additionally, increasing the sulfur content can significantly increase the precipitation temperature of $\mathrm{MnS}$ in bearing steel, increasing the stability of MnS inclusions and reducing the defects caused by the precipitation and dissolution of MnS during high-temperature heating. This improves the processing performance of bearing steel.

\section{Conclusions}

Most composite inclusions in bearing steel contain an MnS component. The proportion of MnS in composite inclusions gradually decreases when the size of the inclusion area is increased. The inclusion shape changes from a particle shape to a strip shape when the content of sulfur in steel is increased.

The projection diagram of the liquid phase of the $\mathrm{Al}_{2} \mathrm{O}_{3}-\mathrm{CaO}-\mathrm{MgO}-\mathrm{MnS}$ system was calculated by Factsage. With an increase in $\mathrm{MnS}$ content, the ratio of $\mathrm{Al}_{2} \mathrm{O}_{3}$ in the $\mathrm{Al}_{2} \mathrm{O}_{3}-\mathrm{CaO}-\mathrm{MgO}-\mathrm{MnS}$ quaternary inclusion system reduced significantly, especially when the $\mathrm{MnS}$ proportion reached more than $20 \%$. Therefore, a proper increase in the sulfur content of bearing steel can make $\mathrm{Al}_{2} \mathrm{O}_{3}$ inclusions in steel finer and more dispersed.

The sulfur content of bearing steel has a significant effect on the precipitation temperature of MnS. When the sulfur content increases from $0.001 \%$ to $0.007 \%$, the precipitation temperature of MnS increases from 1493 to $1633 \mathrm{~K}$, the precipitation of MnS changes from an austenite solid to a combination of liquid and solid and the precipitation size of the MnS inclusions increases significantly.

Bearing steel can be manipulated using a composition of high sulfur and low oxygen to improve its fatigue performance. MnS has an obvious wrap effect on the inclusion of small-scale oxides in bearing steel. To enhance the positive role of sulfur content in bearing steel, we should strictly control the oxygen content in steel while appropriately increasing the sulfur content.

Author Contributions: Conceptualization, H.Z. and G.F.; data curation, H.Z.; formal analysis, H.Z.; investigation, H.Z., B.W. and X.L. (Xuming Liu); methodology, H.Z.; project administration, X.L. (Xin Liu); resources, G.F.; supervision, G.F.; writing-original draft, H.Z.; writing-review and editing, X.L. (Xin Liu), B.W. and X.L. (Xuming Liu). All authors have read and agreed to the published version of the manuscript.

Funding: This research received no external funding.

Acknowledgments: Special thanks to the new materials manufacturing team from the Central Iron \& Steel Research Institute for their great help on the aspects tests of metallographic testing, ASPEX testing and fatigue properties tests. This research was supported by a factory project, which is devoted to the research and development of bearing steel in Jiangsu.

Conflicts of Interest: The authors declare no conflict of interest.

\section{References}

1. E Silva, A.C. Non-metallic inclusions in steels-origin and control. J. Mater. Res. Technol. 2018, 3, $283-299$. [CrossRef]

2. Ånmark, N.; Karasev, A.; Jönsson, P.G. The effect of different non-metallic inclusions on the machinability of steels. Materials 2015, 8, 751-783. [CrossRef] [PubMed] 
3. Xiao, G.H.; Dong, H.; Wang, M.Q.; Hui, W.J. Effect of sulfur content and sulfide shape on fracture ductility in case hardening steel. J. Iron Steel Res. Int. 2011, 18, 58-64. [CrossRef]

4. Nakayama, T.; Honjou, N.; Minaga, T.; Yashiki, H. Effects of manganese and sulfur contents and slab reheating temperatures on the magnetic properties of non-oriented semi-processed electrical steel sheet. J. Magn. Magn. Mater. 2001, 234, 55-61. [CrossRef]

5. Domizzi, G.; Anteri, G.; Ovejero-Garcia, J. Influence of sulphur content and inclusion distribution on the hydrogen induced blister cracking in pressure vessel and pipeline steels. Corros. Sci. 2001, 43, 325-339. [CrossRef]

6. Lijie, Y.; Longmei, W.; Jinsheng, H. Effects of rare earth on inclusions and corrosion resistance of 10PCuRE weathering steel. J. Rare Earths 2010, 28, 952-956.

7. Lin, S.-G.; Yang, H.-H.; Su, Y.-H.; Chang, K.-L.; Yang, C.-H.; Lin, S.-K. CALPHAD-assisted morphology control of manganese sulfide inclusions in free-cutting steels. J. Alloy. Compd. 2019, 779, 844-855. [CrossRef]

8. Nagels, E.; Duflou, J.R.; Van Humbeeck, J. The influence of sulphur content on the quality of laser cutting of steel. J. Mater. Process. Technol. 2007, 194, 159-162. [CrossRef]

9. Hashimoto, K.; Fujimatsu, T.; Tsunekage, N.; Hiraoka, K.; Kida, K.; Santos, E.C. Study of rolling contact fatigue of bearing steels in relation to various oxide inclusions. Mater. Des. 2011, 32, 1605-1611. [CrossRef]

10. Kim, D.; Han, K.; Lee, B.; Han, I.; Park, J.H.; Lee, C. Oxide formation mechanisms in high manganese steel welds. Metall. Mater. Trans. A 2014, 45, 2046-2054. [CrossRef]

11. Xiao, W.; Wang, M.; Bao, Y. The Research of Low-Oxygen Control and Oxygen Behavior during RH Process in Silicon-Deoxidization Bearing Steel. Metals 2019, 9, 812. [CrossRef]

12. Gu, C.; Lian, J.; Bao, Y.; Xie, Q.; Münstermann, S. Microstructure-based fatigue modelling with residual stresses: Prediction of the fatigue life for various inclusion sizes. Int. J. Fatigue 2019, 129, 105158. [CrossRef]

13. Sadeghi, F.; Jalalahmadi, B.; Slack, T.S.; Raje, N.; Arakere, N.K. A Review of Rolling Contact Fatigue. J. Tribol. 2009, 131, 041403. [CrossRef]

14. Gu, C.; Wang, M.; Bao, Y.; Wang, F.-M.; Lian, J. Quantitative analysis of inclusion engineering on the fatigue property improvement of bearing steel. Metals 2019, 9, 476. [CrossRef]

15. Zhang, X.; Yang, S.; Li, J.; Wu, J. Transformation of oxide inclusions in stainless steel containing yttrium during isothermal heating at $1473 \mathrm{~K}$. Metals 2019, 9, 961. [CrossRef]

16. Wang, F.; Guo, H.; Liu, W.; Yang, S.; Zhang, S.; Li, J. Control of MnS inclusions in high-and low-sulfur steel by tellurium treatment. Materials 2019, 12, 1034. [CrossRef]

17. Shin, J.H.; Park, J.H. Formation mechanism of oxide-sulfide complex inclusions in high-sulfur-containing steel melts. Metall. Mater. Trans. B 2018, 49,311-324. [CrossRef]

18. Doostmohammadi, H.; Jönsson, P.; Komenda, J.; Hagman, S. Inclusion characteristics of bearing steel in a runner after ingot casting. Steel Res. Int. 2010, 81, 142-149. [CrossRef]

19. You, D.; Michelic, S.; Bernhard, C.; Loder, D.; Wieser, G. Modeling of inclusion formation during the solidification of steel. ISIJ Int. 2016, 56, 1770-1778. [CrossRef]

20. Chen, P.-J.; Zhu, C.-Y.; Li, G.; Dong, Y.-W.; Zhang, Z.-C. Effect of sulphur concentration on precipitation behaviors of MnS-containing inclusions in GCr15 bearing steels after LF refining. ISIJ Int. 2017, 57, 1019-1028. [CrossRef]

21. Drar, H. Metallographic and fractographic examination of fatigue loaded PM-steel with and without MnS additive. Mater. Charact. 2000, 45, 211-220. [CrossRef]

22. Scurria, M.; Emre, S.; Möller, B.; Wagener, R.; Melz, T. Evaluation of the influence of MnS in forged steel 38MnVS6 on fatigue life. SAE Int. J. Engines 2017, 10, 366-372. [CrossRef]

23. Wang, J.; Ren, Q.; Luo, Y.; Zhang, L. Effect of non-metallic precipitates and grain size on core loss of non-oriented electrical silicon steels. J. Magn. Magn. Mater. 2018, 451, 454-462. [CrossRef]

24. Bhadeshia, H.K.D.H. Steels for bearings. Prog. Mater. Sci. 2012, 57, 268-435. [CrossRef]

25. Tian, C.; Liu, J.-H.; Lu, H.-C.; Dong, H. Estimation of maximum inclusion by statistics of extreme values method in bearing steel. J. Iron Steel Res. Int. 2017, 24, 1131-1136. [CrossRef]

26. Zhang, J.; Wang, F.; Li, C. Thermodynamic analysis of the compositional control of inclusions in cutting-wire steel. Int. J. Miner. Metall. Mater. 2014, 21, 647-653. [CrossRef]

27. Ghosh, A. Thermodynamic evaluation of formation of oxide-sulfide duplex inclusions in steel. ISIJ Int. 2008, $48,1552-1559$. 
28. Huang, X.H. The Principle of Ferrous Metallurgy, 4th ed.; Metallurgical Industry Press: Beijing, China, 2005; p. 181.

29. Choudhary, S.K.; Ghosh, A. Fundamentals of high temperature processes-mathematical model for prediction of composition of inclusions formed during solidification of liquid steel. ISIJ Int. 2009, 49, 1819. [CrossRef]

30. Gao, Y.; Han, H.; Zhang, X. Measurement of P-S-N curve of contact fatigue of specially strengthened GCr15 steel ball. Bearings 2005, 8, 27-28.

31. Gao, S.; Wang, G.; Qu, S. Research on contact fatigue performance of bearing steel. Mech. Eng. Autom. 2014, 184, 105-107.

32. Yang, C.; Luan, Y.; Li, D.; Li, Y. Very high cycle fatigue properties of bearing steel with different aluminum and sulfur content. Int. J. Fatigue 2018, 116, 396-408. [CrossRef]

33. Yang, C.; Liu, P.; Luan, Y.; Li, D.; Li, Y. Study on transverse-longitudinal fatigue properties and their effective-inclusion-size mechanism of hot rolled bearing steel with rare earth addition. Int. J. Fatigue 2019, 128, 105193. [CrossRef]

(C) 2020 by the authors. Licensee MDPI, Basel, Switzerland. This article is an open access article distributed under the terms and conditions of the Creative Commons Attribution (CC BY) license (http://creativecommons.org/licenses/by/4.0/). 